\title{
Coding of Luminance and Color Differences on Neurons in the Rabbit's Visual System
}

\author{
Dmitry V. Evtikhin, Vladimir B. Polianskii, Dzekshen E. Alymkulov, and Evgenii N. Sokolov† \\ Moscow State University (Russia)
}

\begin{abstract}
The neuronal activity in the rabbit's visual cortex, lateral geniculate nucleus and superior colliculus was investigated in responses to 8 color stimuli changes in pairs. This activity consisted of phasic responses (50-90 and 130-300 Ms after stimuli changes) and tonic response (after $300 \mathrm{Ms}$ ). The phasic responses used as a basis for the matrices $(8 \times 8)$ constructed for each neuron included the average of spikes/sec in responses to all stimuli changes. All matrices were treated by factor analysis and the basic axes of sensory spaces were revealed. Sensory spaces reconstructed from neuronal spike discharges had a twodimensional (with brightness and darkness axes) or four-dimensional (with two color and two achromatic axes) structure. Thus it allowed us to split neurons into groups measuring only brightness differences and the measuring of color and brightness differences between stimuli. The tonic component of most of the neurons in the lateral geniculate nucleus showed linear correlation with changes in intensities; therefore, these neurons could be characterized as pre-detectors for cortical selective detectors. The neuronal spaces demonstrated a coincidence with spaces revealed by other methods. This fact may reflect the general principle of vector coding (Sokolov, 2000) of sensory information in the visual system.

Keywords: neuronal activity, perceptual space, vector coding, color perception
\end{abstract}

Se examinaron la actividad neuronal en la corteza visual, el núcleo lateral geniculado y el collículo superior del conejo en las respuestas a 8 cambios de estímulos de color en parejas. Esta actividad consistía en respuestas fásicas (50-90 y 130-300 Ms después del cambio estimular) y respuesta tónica (después de $300 \mathrm{Ms})$. Las respuestas fásicas empleadas como una base para las matrices $(8 \times 8)$ construidas para cada neurona incluían la media de picos/segundo en respuestas a todos los cambios estimulares. Todas las matrices fueron tratadas por análisis factorial y se pusieron de manifiesto los ejes básicos de espacios sensoriales. Los espacios sensoriales reconstruidos de las descargas neuronales pico tenían una estructura bi-dimensional (con ejes de brillo y oscuridad) o de cuatro dimensiones (con dos ejes de color y dos ejes acromáticos). Así, nos permitió dividir las neuronas en grupos que sólo medían las diferencias en brillo y los que medían las diferencias entre los estímulos en color y brillantez. El componente tónico de la mayoría de las neuronas en el núcleo geniculado lateral mostraron una correlación linear con los cambios en las intensidades: de ahí, estas neuronas se podrían caracterizar como pre-detectores para los detectores corticales selectivos. Los espacios neuronales mostraron una coincidencia con los espacios revelados por otros métodos. Este hecho podría reflejar el principio general de la codificación vectorial (Sokolov, 2000) de la información sensorial en el sistema visual.

Palabras clave: actividad neuronal, espacio perceptual, codificación vectorial, percepción del color

The work was performed with the financial support of the Russian Fund for Fundamental Research (grants Nos.04-04-48345 and 0704-00259).

Correspondence concerning this article should be addressed to Dr. Dmitry Evtikhin, Department of higher nervous activity, Division of Biology, M.V. Lomonosov Moscow State University, Vorobiovy Gory, Moscow, Russia, 119991. E-mail: pol@ neurobiology.ru

How to cite the authors of this article: Evtikhin, D. V., Polianskii, V.B., Alymkulov, D. E. and Sokolov, E.N. 
Over many decades of studying the visual systems of humans and animals, answers were found to many questions associated with the perception of color, intensity, forms, volume, movement and other typical visual stimuli. Studies were made of the pigments in the photoreceptors of the retina, the pathways and centers of the visual analyzer, and the receptive fields of various neurons. However, questions as to how the coding of color and brightness information was accomplished and how neurons react to brightness and color differences in the visual field, at the same time forming a spectrum of chromatic sensations, remain open and unresolved to this day. The hypothesis for vector coding of information in analyzers as proposed by Professor E. N. Sokolov attempts to answer these questions (Izmailov \& Sokolov, 1991; Sokolov, 2000).

Psychophysical experiments on the categorizing of colors and the correlation of color differences by humans were the basis of research for the group under the leadership of Sokolov (Sokolov \& Izmailov, 1984; Izmailov, Sokolov, \& Chernorizov, 1989). The processing of the data by multidimensional scaling and factor analysis allowed the construction of a color perceptive space for man. It represented a hypersphere in a four-dimensional Euclidean space. Individual stimuli in such space were equal in length by vector stimulation. A person can assess the semantic differences between words and express these differences in numbers. On the basis of such assessments four-dimensional color and twodimensional achromatic spaces were constructed. The base axes were interpreted as red-green, blue-yellow, bright and dark channels for information processing. The stimuli presented to a human were arranged on the surface of the hypersphere, and the distance between the points viewed as the subjective differences between corresponding stimuli (Izmailov \& Sokolov, 1991; Izmailov et al., 1989).

The vector coding principle proposed by Sokolov and lying at the base of our proposed hypothesis, assumes that during the perceptual process: 1) the full set of color shades is presented by the maximum stimulations of the detectors along the surface of the hypersphere in 4-dimensional space; 2) the differences between colors are determined by the distances between the ends of the stimulation vectors (Sokolov, 2003). These two assumptions can be tested in a psycho-physiological experiment where the task is presented to the testee to give a number rating of the difference between stimuli presented in pairs. The matrix compiled from the shades of the color differences permits the use of multidimensional scaling and factor analysis to find the base which determines the full set of color vectors and the differences between them. Similar results were expected when compiling matrices of electro-retinogram amplitudes, visual evoked potentials, and also neuron reactions discovered in experiments on animals during replacement of color stimuli. The rabbit is a very suitable subject for physiological research among mammals: it can remain in a tied condition for a long time and at the same time its eyes do not move significantly (Wyrwycz, Chen Li Weiss, \& Disterhoft, 2000).

In our experiments, as an analogue for subjective human assessments, the probability of instrumental reactions of animals was used during conditioned reflex differentiation in series with a single reinforced color and seven differentiations (Evtikhin, Latanov, \& Sokolov, 1997; 1998; Latanov, Leonova, Evtikhin, \& Sokolov, 1997; Polianskii, Sokolov, Marchenko, Evtikhin, \& Ruderman, 1998). Successively resetting the color stimuli in such a way so that each of them was reinforced, a matrix was compiled with cells containing the probability of conditional reactions to differential stimuli presented in pairs with the reinforced color. These probabilities served as the measure of the difference between stimuli, based on the integrity of the animal's behavioral response. The rows of the matrix were viewed as a vector compiled from the probabilities of responses to this or that stimulus presented in a pair with seven others. On the basis of such matrix, a matrix was constructed of the pair correlations between these vectors, which was developed using factor analysis to reveal the base axes of the space of the vectors presenting the stimuli.

Those researches succeeded in constructing color perceptive spaces for various animals (carp, rabbits, monkeys). The spaces of stimuli differing both in color and in brightness had a four-dimensional structure, as in the experiments on humans. In the case of trichromatic animals (fishes, monkeys), the color space principally coincided with that obtained for man (Evtikhinet al., 1997; 1998; Latanov et al., 1997). In the case of dichromatic animals (the rabbit lacks a red-absorbing pigment in the retina), the perceptive space also had a four-dimensional structure, however, the red-green and blue-yellow axes were subject to reduction in the red and yellow parts (Polianskii et al., 1998).

The psychophysical data obtained permitted the hypothesis to be advanced of four neuron mechanisms (channels) for information processing and participating in the analysis of visual color information. Objective electroand neurophysical data could serve as confirmation of the said hypothesis. Electrophysiological research on rabbits was conducted by our group. The result of these tests was the construction of sensory spaces based on the processing of the said visual evoked potentials registered in the rabbit's visual cortex in response to a change in the color stimuli of a different color and brightness. Two sets of stimuli were used in the experiments: 8 variously-bright color stimuli and 8 black-and-white (differing only in intensity), replacing one another on a monitor screen and illuminating the whole retina of the animal's eye. Always observed in the rabbit's VEP (visual evoked potentials) was the early component N85: both during a change in color stimuli, and where there was a change in stimuli differing only in intensity. It was discovered that the amplitude of component N85 correlates to the amount of brightness and color differences between stimuli (Polianskii, Evtikhin, \& Sokolov, 1999). The 
amplitude of this component was used as a measure between stimuli, compiling matrices according to the principle described for conditioned reflex responses.

After the VEP amplitudes were compiled in a $8 \times 8$ matrix and subjected to factor analysis, it appeared that the rabbit's color space, reconstructed according to the amounts of component N85 during changes in color stimuli, forms a hypersphere in a four-dimensional Euclidean space (Polianskii, Evtikhin, \& Sokolov, 2000). The sensory spaces of color stimuli induced according to the VEP data for the rabbit principally coincided with spaces for human protanomaly obtained during analysis of component N87 of the evoked potential (Vartanov, Polianskii, Sokolov, \& Evtikhin, 1998). Such a coincidence confirmed the general mechanisms for color perception for a dichromate rabbit and a human with anomalous lack of pigment in the retina.

The given work is devoted to research into the reactions of individual neurons located at various levels of the visual analyzer. The rabbit (Oryctolagus cuniculus) was chosen as the experimental animal subject - an animal with dichromatic vision and the absence in the retina of a pigment absorbing light in the long-wave ('red') range (Jacobs, 1993; Nuboer \& Moed, 1983; Nuboer, van Nuys, \& Wortel, 1983). In the beginning a test was conducted of the neurons in the visual cortex of the rabbit as the higher section of the visual analyzer, and then the neurons of the thalamic relay nucleus studied - the lateral geniculate nucleus (LGN), and also of the sub-cortical visual centre - the superior colliculus (SC). The aim of the work was the comparison of neuron responses of these structures both to changes in stimuli differing only in intensity, and also to changes in stimuli differing both in intensity and color tone.

\section{Method}

The experiments with animals were conducted in strict accordance with international legislation on the use of experimental animals. The researchers were guided by recommendations of the code of ethics adopted by the Council for International Organizations of Medical Sciences in 1985, and also by Russian legislation in the field of biomedicine.

\section{Subjects and Procedure}

Experiments were conducted on 16 male rabbits aged 2-3 years. For the placement of a duct for the animal's micromanipulator, an operation was carried out under Nembutal anaesthesia $(40 \mathrm{mg} / \mathrm{kg}$ ) and local anaesthetic (novocaine, $2 \%$ ). Using a cutter, a round opening was cut in the skull $5 \mathrm{~mm}$ in diameter (the coordinates of the centre of the opening and the depth of submersion of electrodes for the visual cortex are: $\mathrm{AP}=10, \mathrm{~L}=7, \mathrm{H}=1-1.5$; for the LGN AP $=7.9, \mathrm{~L}=4.9, \mathrm{H}=6.3-6.5$; and for the superior colliculus $\mathrm{AP}=13.5, \mathrm{~L}=2.2, \mathrm{H}=2.3-2.5)$. The duct was a hollow cylinder made of organic glass with an internal diameter of approximately $7 \mathrm{~mm}$, and fixed into the skull with acrylic plastic and covered with a sterile mixture of wax and Vaseline. Passive electrodes were implanted into the frontal bone. The mechanical micromanipulator in the experiment was fixed to the duct and extra-cellular removal of the activity of neurons produced with tungsten electrodes having a tip diameter of 1-2 $\mu \mathrm{m}$.

In the experiments, the rabbit was placed in a wooden stand; its head fixed using bandages. The rabbit could calmly remain in this condition for several hours and its eyes not make any significant movements. The rabbit was placed in a screened sound-proof chamber at a distance of $50 \mathrm{~cm}$ from the screen of a cathode-ray color SVGA monitor (made by TVM, Taiwan) with a frame-scan frequency of $70 \mathrm{~Hz}$. The photostimulation was monocular and diffused, and the screen size of the monitor was $25 \times 20 \mathrm{~cm}$. Recording of the neurons' activity was made from the hemisphere contralateral to the stimulated eye.

The signal was amplified on an amplifier and then fell onto a two-window discriminator which permitted the signal not only to be separated from noise using the amplitude window, but also more precisely to separate the signal of a determined neuron using the second window, movable relative to the beginning of the impulse, i.e., having the capability to select the section typical for the spikes of the actual neuron.

The experiment setup consisted of two synchronized computers, (PC-AT IBM-386) served to supply the stimuli, the other (Pentium-4) - to administer the experiment and process the results. After discrimination, the signals were sent to an analogue-digital converter in the Pentium-4 computer.

The experiment used eight variously-bright color stimuli replacing each other in pairs: white, red, yellow, yellowgreen, green, blue-green, blue, and black, in all 64 pairs (including substitution of identical stimuli). The specifications of the stimuli obtained using a television color analyzer and luminance meter (TKYa, Russia), and also the RGB-relationship of the monitor's color guns, are presented in Table 1. The white, yellow, yellow-green and green stimuli were able to be leveled according to subjective brightness for the rabbit. Such leveling of the stimuli was conducted analyzing the amount of N85 and P130 components of the rabbit's visual evoked potentials (VEP) under the pair changes of stimuli of various colors, one of which (the reference) was of a fixed brightness, and the brightness of the other (test) varying in wide ranges. In the event of equal brightness between the test and reference stimuli, the amplitude of the component was minimal (Polianskii et al., 1999).

Apart from variously-bright stimuli, also used were 64 combinations of stimuli of one color tone (white), but of various intensity (eight gradations of intensity - from 4 to $19 \mathrm{Cd} / \mathrm{m}^{2}$ ). The duration of each stimulus was $1.5 \mathrm{sec}$., and each pair of stimuli was used in the experiment 20 times. 
Table 1

Color and Photometric Characteristics Of Stimuli Presented to Rabbit during Experiments

\begin{tabular}{|c|c|c|c|c|}
\hline \multirow[b]{2}{*}{ Stimuli } & \multirow[b]{2}{*}{ Hue (8-bit R-G-B) } & \multicolumn{2}{|c|}{ CIE-31 Coordinates } & \multirow[b]{2}{*}{ Intensity, $\mathrm{cd} / \mathrm{m}^{2}$} \\
\hline & & $\mathrm{X}$ & $\mathrm{Y}$ & \\
\hline White & 104-104-104 & 0.280 & 0.305 & 13.5 \\
\hline Red & $200-0-0$ & 0.620 & 0.345 & 12 \\
\hline Yellow & $160-128-0$ & 0.437 & 0.495 & 25 \\
\hline Yellow-green & $108-128-0$ & 0.370 & 0.540 & 20.5 \\
\hline Green & $0-128-0$ & 0.320 & 0.580 & 17.5 \\
\hline Green-blue & $0-128-128$ & 0.228 & 0.300 & 20.5 \\
\hline Blue & $0-0-200$ & 0.154 & 0.066 & 7 \\
\hline Black & $0-0-0$ & 0 & 0 & 0 \\
\hline
\end{tabular}

Neurons were studied, the patterns of responses of which contained one or several phasic discharges. Early discharge in the 50-90 Ms range from the time of replacing the stimuli was more stable and was observed both for neurons in the visual cortex, and also for neurons in sub-cortical structures. For neurons in the superior colliculus, a late discharge in the 120-300 Ms range was also typical. Subsequent processing of the results included the construction for each neuron of a 8x8 matrix, the cells of which contained the average number of impulses in the phasic discharges during replacement of one color with another or of one intensity of color with another. In such matrices of spike reactions, each stimulus was represented by a vector (matrix row) compiled from the average number of spikes in the neuron's discharge to stimuli of the given color (or given intensity) in pairs with other colors (intensities). On the basis of such matrices, matrices were constructed for the correlations between vectors which were then processed using factor analysis with the aim of discovering the coordinates of vectors in the base axes of brightness or color spaces.

\section{Statistical Analyses and Results}

The reactions were recorded of 54 neurons in the visual cortex, 51 neurons in the lateral geniculate nucleus, and also of 83 neurons in the rabbits' superior colliculus. From the whole population of neurons recorded by us, cells were selected in the response patterns of which phasic discharges to changes of stimuli were observed. Presented in Figure 1 are examples of the reactions to various changes. From Figure 1.A it is seen that for cells in the visual cortex, a phasic discharge was typical in the 50-90 Ms range after the change of stimuli, after which there followed an inhibitory pause in the interval of 100$220 \mathrm{Ms}$, and then for the overwhelming majority of neurons a second discharge was observed in the range of $220-350 \mathrm{Ms}$, after which tonic activity followed. The amount of initial phasic discharge correlated with the interstimulus difference: this is well noted in experiments with changes of colors of one spectral composition, but different intensity. The greater the interstimulus difference, the greater is the early phasic response of the neuron; such a principle was not discovered for the second discharge. In the case of a change in identical stimuli, a phasic response of the neuron was completely absent, and only a tonic discharge was observed. Patterns of neurons' responses in the lateral geniculate nucleus, on the whole, were reminiscent of the responses in the visual cortex. The dissimilarity from the cortical neurons was in the preponderance of neurons with only one early phasic discharge (range of 40$90 \mathrm{Ms}$ ); in the event a second discharge was also observed, its magnitude was minor (Figure 1.B). The main mass of neurons in the superior colliculus was characterized by patterns including a small early discharge (60-100 Ms), an inhibitory pause, and a large second discharge in the interval of 220$400 \mathrm{Ms}$ and more (Figure 1.C).

On the basis of a calculation of the average number of spikes in the initial phasic discharge ('difference discharge'), for all neurons matrices were compiled in which each stimulus was represented by a seven-component vector (matrix row) comprised of the amount of discharge (spikes/sec) in response to the replacement of this stimulus by seven others (Table 2.A). On the basis of these matrices, matrices were developed of pair correlations between the vectors representing the stimuli (Table 2.B). The latter were elaborated using factor analysis with the aim of discovering the base axes of the sensory space for an individual neuron. Presented in Figure 2 is the two-dimensional sensory space of an individual neuron in the rabbit's visual cortex, reconstructed on the basis of the spike discharges (according to data presented in Table 2), the dispersion of the revealed factors, and also factor loadings which serve as coordinates of stimuli in an individual neuron's sensory space. In the case of a given cortical neuron (Figure 2, Table 2), 3 factors were revealed. Two factors described over $92 \%$ of dispersion of the experimental data, their own values exceeding the unit, thus, meaningful interpretation of the space was limited to these factors. The coordinates of stimuli in the sensory space were calculated according to the factor loads of the significant factors. 

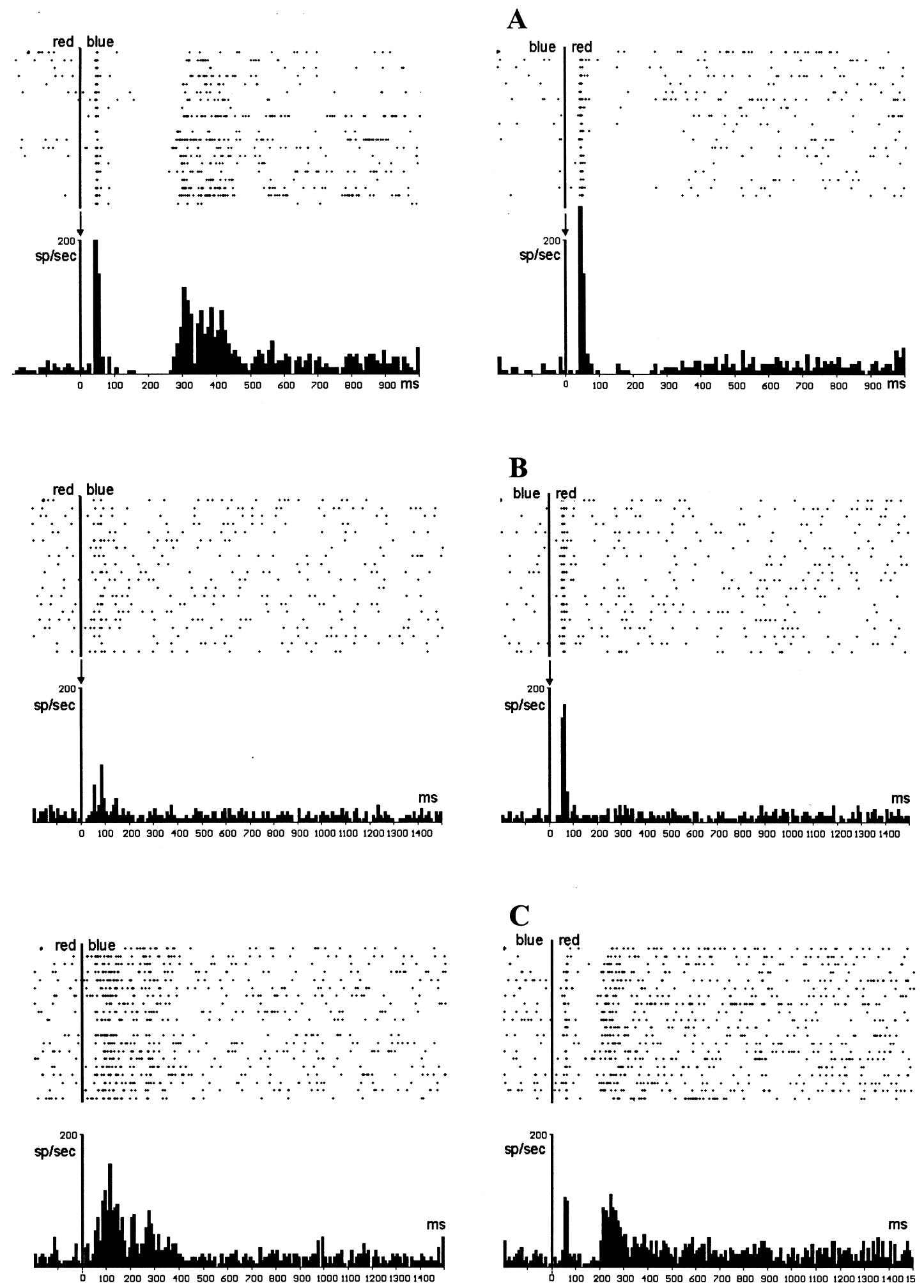

Figure 1. Examples of neuron response patterns to changes in color stimuli: raster and histograms. The vertical lines in every picture mark a moment of stimuli change. Abscissa: time in Ms after change; ordinate: spike discharge (sp/sec). Histogram's bin - 10 Ms.

A. Reactions of cortical neuron No. 34 during red-to-blue changes (left column) and blue-to-red changes (right column).

B. Reactions of neuron in lateral geniculate nucleus No. 46 for color stimuli changes (stimulation as in A).

C. Reactions of neuron in superior colliculus No. 64 for color stimuli changes (stimulation as in A).

D. Reactions of neuron in superior colliculus No. 46 for identical color stimuli changes. 
Table 2

A. The Matrix of Spike Discharge in Earliest Response (50-90 Ms after Stimuli Changes) for Single Cortical Neuron $N^{\circ} 34$. In such Matrix, every Stimulus is Represented as a Vector (Lines in Matrix), Consisting of Neuronal Spike Discharge during Changes from this Stimulus to 7 Others.

B. The Correlation Matrix Calculated by Correlations between Vectors in Pairs, which Represent Stimuli in Table A.

A

\begin{tabular}{ccccccccr}
\hline Stimuli, $\mathrm{Cd} / \mathrm{m}^{2}$ & \multicolumn{1}{c}{$\mathbf{4}$} & $\mathbf{6}$ & $\mathbf{8}$ & $\mathbf{1 0 . 5}$ & $\mathbf{1 2}$ & $\mathbf{1 3 . 5}$ & $\mathbf{1 5}$ & $\mathbf{1 9}$ \\
\hline $\mathbf{4}$ & & 50 & 81.25 & 115 & 122.2 & 138.9 & 189 & 184.2 \\
$\mathbf{6}$ & 57.9 & & 42.1 & 70.6 & 94.7 & 77.8 & 189 & 152.6 \\
$\mathbf{8}$ & 123.5 & 55.6 & & 22.2 & 70.6 & 68.4 & 132 & 133.3 \\
$\mathbf{1 0 . 5}$ & 185 & 121.1 & 70.6 & & 25 & 50 & 38.9 & 136.8 \\
$\mathbf{1 2}$ & 188.9 & 179 & 70.6 & 10.5 & & 36.8 & 36.8 & 121.1 \\
$\mathbf{1 3 . 5}$ & 190 & 173.7 & 142.1 & 42.1 & 68.4 & & 26.3 & 117.7 \\
$\mathbf{1 5}$ & 170 & 195 & 205.3 & 100 & 60 & 83.3 & & 82.4 \\
$\mathbf{1 9}$ & 177.8 & 210 & 205.6 & 155.6 & 163.2 & 164.7 & 52.9 & \\
\hline
\end{tabular}

B

\begin{tabular}{ccccccccc}
\hline Stimuli, $\mathrm{Cd} / \mathrm{m}^{2}$ & $\mathbf{4}$ & $\mathbf{6}$ & $\mathbf{8}$ & $\mathbf{1 0 . 5}$ & $\mathbf{1 2}$ & $\mathbf{1 3 . 5}$ & $\mathbf{1 5}$ & $\mathbf{1 9}$ \\
\hline $\mathbf{4}$ & & & & & & & & \\
$\mathbf{6}$ & .949 & & & & & & \\
$\mathbf{8}$ & .774 & .603 & & & & & \\
$\mathbf{1 0 . 5}$ & -.167 & -.203 & .348 & & & & \\
$\mathbf{1 2}$ & -.411 & -.141 & .325 & .922 & & & \\
$\mathbf{1 3 . 5}$ & -.644 & -.547 & .17 & .819 & .903 & & \\
$\mathbf{1 5}$ & -.802 & -.689 & .039 & .435 & .521 & .768 & \\
$\mathbf{1 9}$ & -.926 & -.979 & -.528 & .435 & .502 & .754 & .8 & \\
\hline
\end{tabular}

A

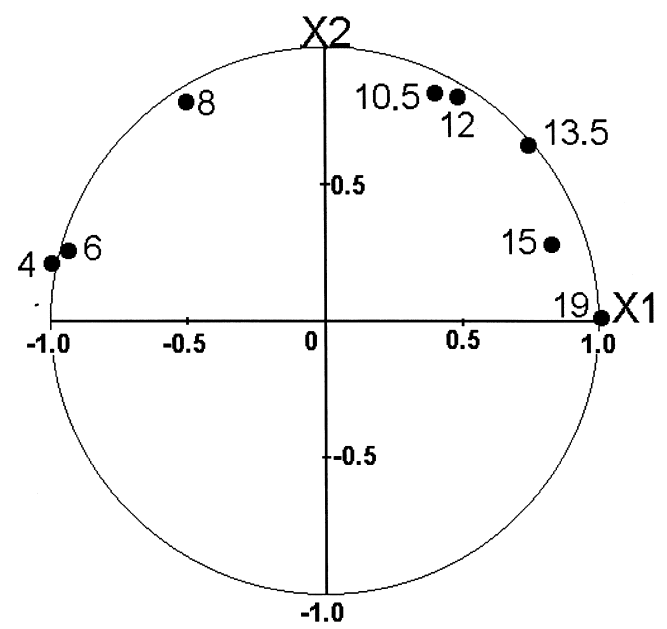

B

\begin{tabular}{|c|c|c|c|}
\hline Factor & $\mathbf{1}$ & $\mathbf{2}$ & $\mathbf{3}$ \\
\hline Eigenvalue of factors & 4.95 & 2.46 & 0.55 \\
\hline Dispersion, \% & 61.89 & 30.76 & 6.92 \\
\hline Total dispersion, \% & 61.89 & 92.65 & 99.57 \\
\hline
\end{tabular}

C

\begin{tabular}{|c|c|c|}
\hline $\begin{array}{c}\text { Stimuli, } \\
\mathbf{c d} / \mathbf{m}^{2}\end{array}$ & $\begin{array}{c}\text { Factor loadings in two-dimensional } \\
\text { sensory space }\end{array}$ \\
\cline { 2 - 3 } & $\mathbf{X 1}$ & $\mathbf{X 2}$ \\
\hline $\mathbf{4}$ & -0.994 & 0.212 \\
\hline $\mathbf{6}$ & -0.932 & 0.256 \\
\hline $\mathbf{8}$ & -0.503 & 0.801 \\
\hline $\mathbf{1 0 . 5}$ & 0.403 & 0.835 \\
\hline $\mathbf{1 2}$ & 0.489 & 0.824 \\
\hline $\mathbf{1 3 . 5}$ & 0.749 & 0.646 \\
\hline $\mathbf{1 5}$ & 0.833 & 0.287 \\
\hline $\mathbf{1 9}$ & 1.010 & 0.013 \\
\hline
\end{tabular}

Figure 2. The sensory space of single rabbit's individual cortical neuron No. 34, reconstructed on the basis of spike discharges during 50-90 Ms after stimuli change. The data for the spike discharges are presented in Table 2.

A. The sensory space of stimuli differing in intensity. The numbers in the diagram indicate the bightness of stimuli, $\mathrm{Cd} / \mathrm{m}^{2}$.

B. Eigenvalues and dispersion of marked factors.

C. Factor loads (stimuli' coordinates in the space) calculated by factor analysis on the basis of spike discharges (according to Table 2). 

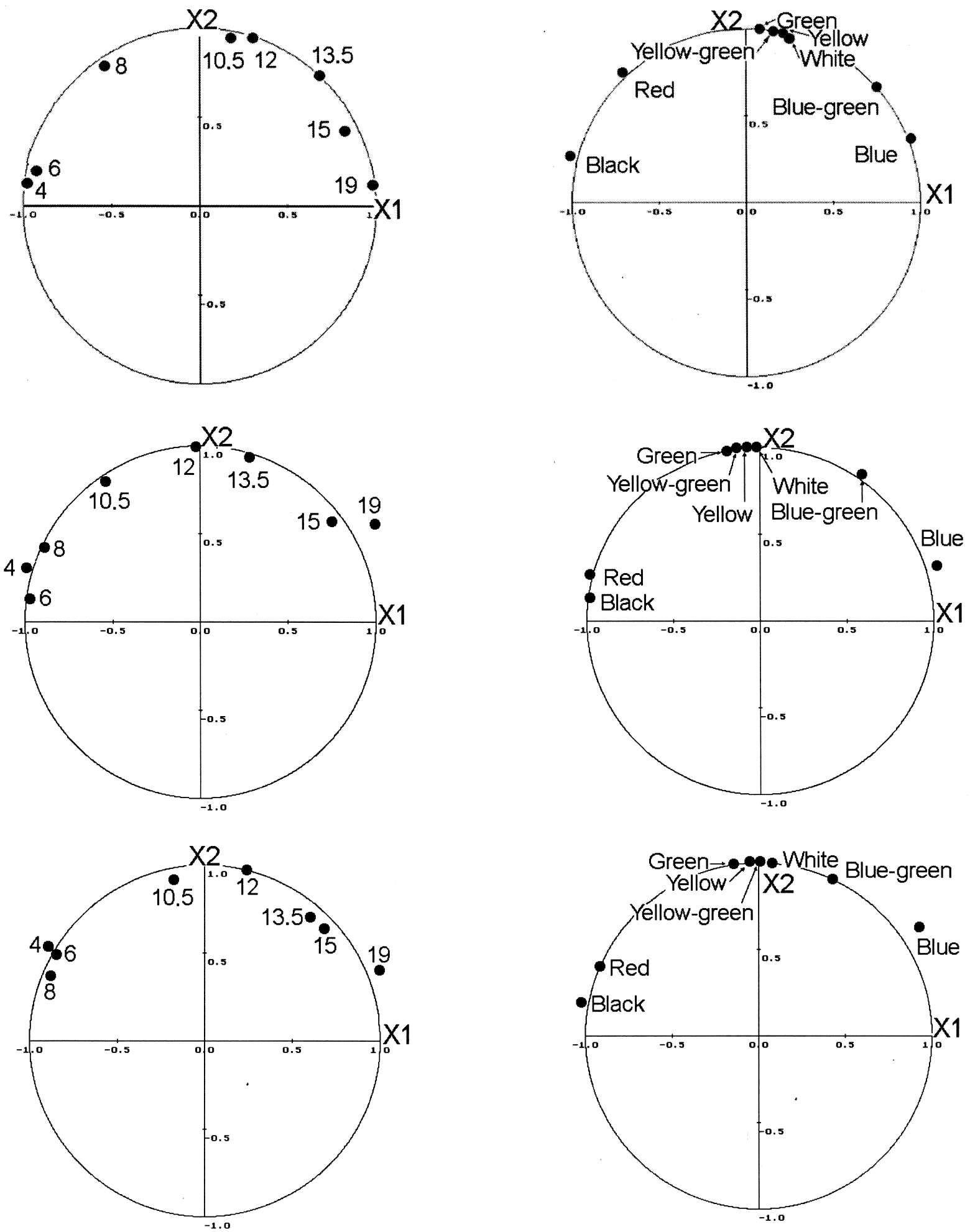

Figure 3. Averaged achromatic spaces for stimuli of the same color tone, but different intensity.

A. Sensory space for cortical neuron No. 34 .

B. Sensory space for neurons in lateral geniculate nucleus (averaged for 24 neurons);

C. Sensory space for neurons in superior colliculus (averaged for 7 neurons).
Figure 4. Averaged achromatic spaces for color stimuli.

A. Sensory space for cortical neurons (averaged for 16 neurons);

B. Sensory space for neurons in lateral geniculate nucleus (averaged for 45 neurons);

C. Sensory space for neurons in superior colliculus (averaged for 20 neurons). 
It transpired that for neurons of all studied structures, where there were changes in the stimuli differing only in intensity, the sensory space had a two-dimensional structure. Data on such neurons were averaged, as a result of which for neurons in the lateral geniculate nucleus and the superior colliculus the averaged sensor spaces were reconstructed, as presented in Figure 3. As is clear from Figure 3, the achromatic spaces of neurons on different sections of the visual analyzer were principally alike. Stimuli in such a space are arranged on an arch from the least intensity to the greatest. The central angle between the stimuli is viewed as the measure of the subjective difference between the stimuli. The insignificant differences can be explained by the difficulties arising when distinguishing stimuli under weak and highly bright values of presented stimuli.

In the case when variously bright color stimuli were used, sensory spaces were reconstructed based on the basis of the neurons' responses having either a 4-dimensional structure, i.e., reflecting the interaction of four different factors, or twodimensional spaces typical for stimuli of one spectral composition, but of equal intensity. In the case of the 2dimensional solution, stimuli were arranged on an arc of approximately $180^{\circ}$ in a manner corresponding to the intensity of the color stimuli: from dark (black and red) to bright (bluegreen and blue). Stimuli leveled in intensity for the rabbit (Polianskii et al., 1999) were grouped together in a meanvalue area (Figure 4). The detection of such two-dimensional spaces obtained for variously-bright stimuli of different spectral compositions testifies to the fact that these neurons only participate in processing information on a change in the intensity of stimuli. The percentage ratio of such neurons in different sections of the analyzer was unequal: the twodimensional space of color stimuli was able to be reconstructed for $30 \%$ of neurons in the visual cortex and superior colliculus, but for neurons in the LGN this percentage was much larger $-86 \%$. It must be noted that two-dimensional spaces were always reconstructed according to the early (50-90 Ms) discharge, at the same time as 4-dimensional spaces were able to be reconstructed according to both the early and also the later discharges. The latter proved especially typical for neurons in the superior colliculus.

In the visual cortex, for $22 \%$ of neurons a 4-dimensional color space could be reconstructed according to the early discharge, in the geniculate nucleus a similar space was reconstructed for $14 \%$ of neurons, but in the superior colliculus the spaces for $4 \%$ of neurons was 4-dimensional (according to the initial discharge) and for $15 \%$ of neurons (according to the secondary discharge in a range of 120$250 \mathrm{Ms}$ ). Presented in Figure 5 are the different projections of averaged 4-dimensional spaces of neurons on the plane of revealed factors: two factors were interpreted as color (Figure 5.A), and two as achromatic (Figure 5.B). From this diagram it is clear that color sensory spaces reconstructed on the basis of spike discharges in neurons in different sections of the visual analyser also principally coincide. The two color factors (X1 and X2) are presented on the color plane of the actual semi-axes (blue and green). These factors are interpreted by us as opposing red-green and blue-yellow mechanisms typical for trichromatic animals and humans (Izmailov \& Sokolov, 1991; Latanov et al., 1997), but reduced and presented in the space as the semi-axes for the dichromate
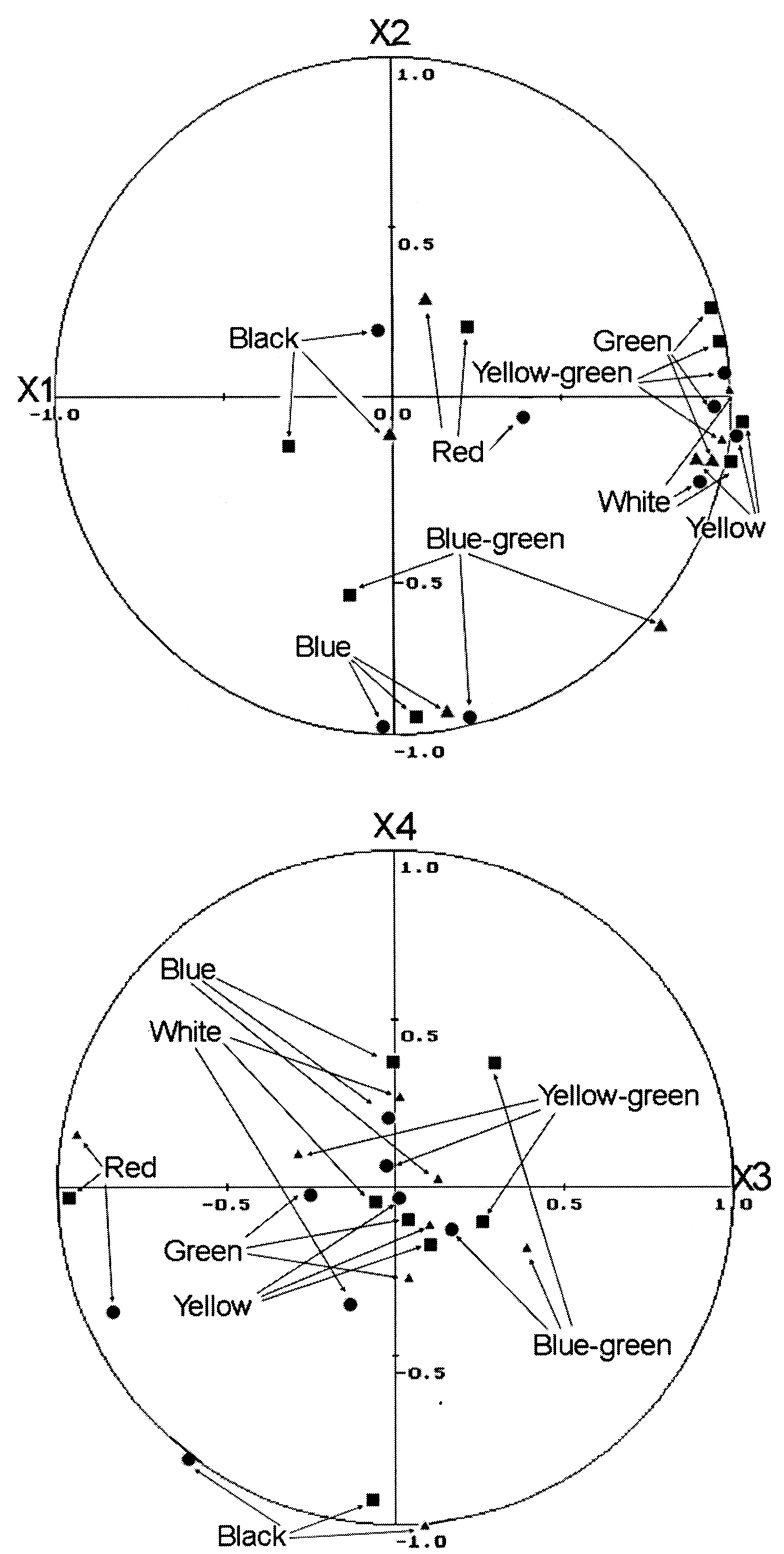

Figure 5. Projections of neurons' four-dimensional sensory spaces on planes of revealed factors. Squares indicate the averaged data from 12 cortical neurons; triangles indicate averaged data from 7 neurons in the lateral geniculate nucleus; circles indicate averaged data from 12 neurons in the superior colliculus.

A. The projection of stimuli points on the color plane (factors X1 and $\mathrm{X} 2$ ).

B. The projection of stimuli points on the achromatic plane (X3 and $\mathrm{X} 4)$. 
rabbit. The reduction of the red pigment in the retina leads to the red stimulus being perceived as achromatic and offset in the rabbit towards the centre of the projection on the color plane. Other stimuli, in the composition of which there is a long-wave component (yellow, yellow-green), are offset to the area of green colors. Thus, the rabbit's color plane is reduced to a single quadrant in comparison with the color plane of trichromates (Latanov et al., 1997).
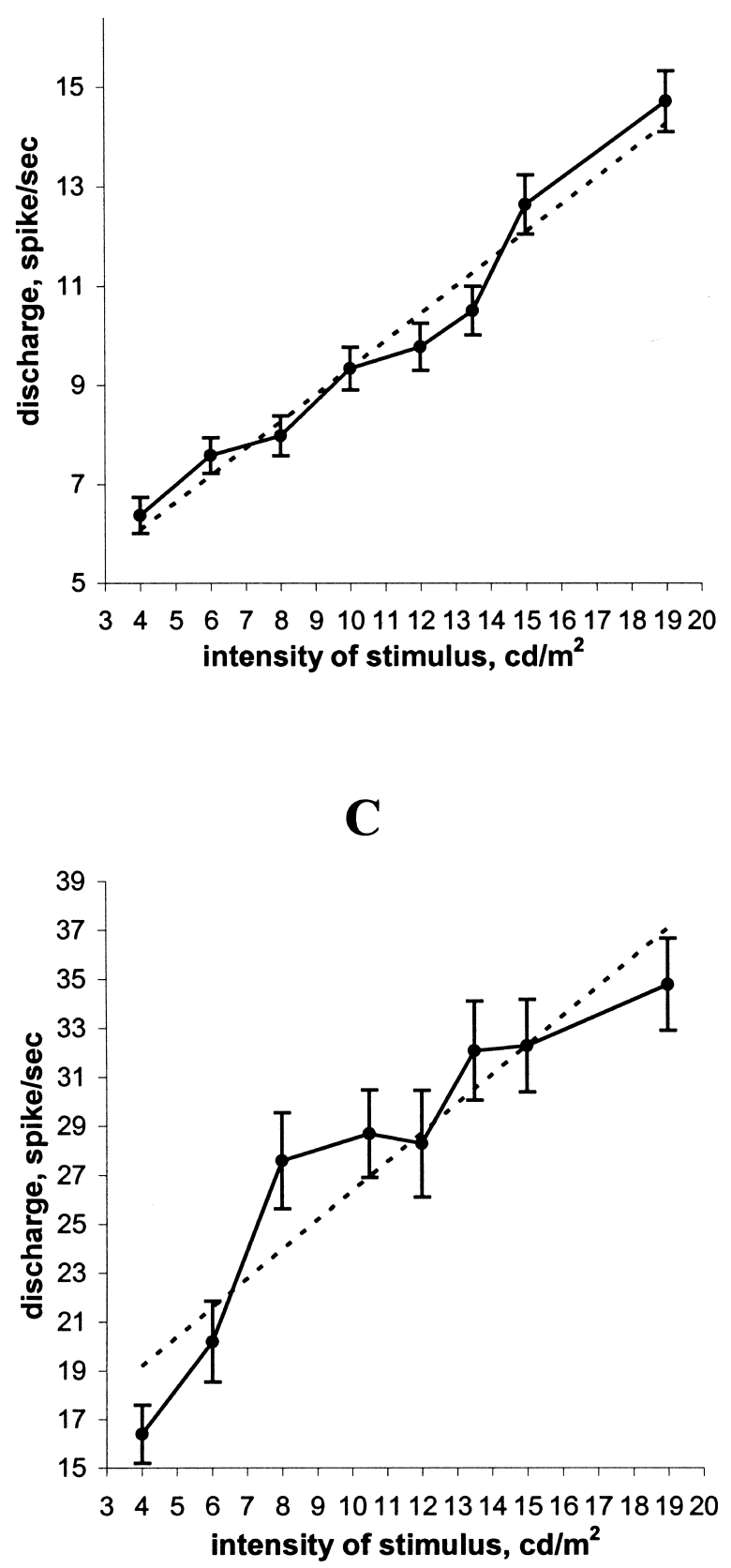

The second projection (factors X3 and X4) is viewed by us as an achromatic plane: here, the stimuli, having a larger coordinate on the color plane are offset towards the centre of the projection, and stimuli located in the centre of the color plane (red and black) and being achromatic for the rabbit, have large coordinates.

Apart from studying the properties of the neurons' phasic discharges, we conducted an analysis of the neurons' tonic

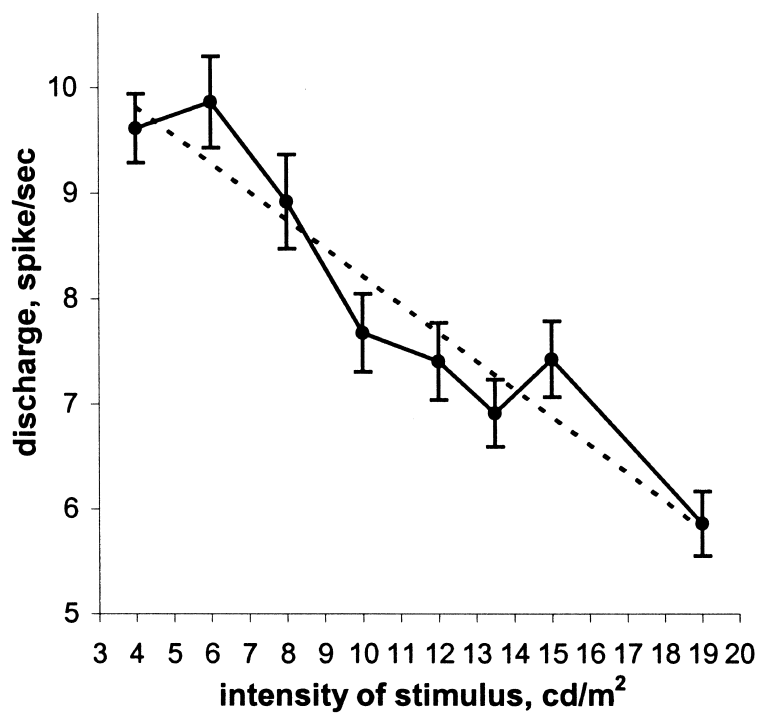

D

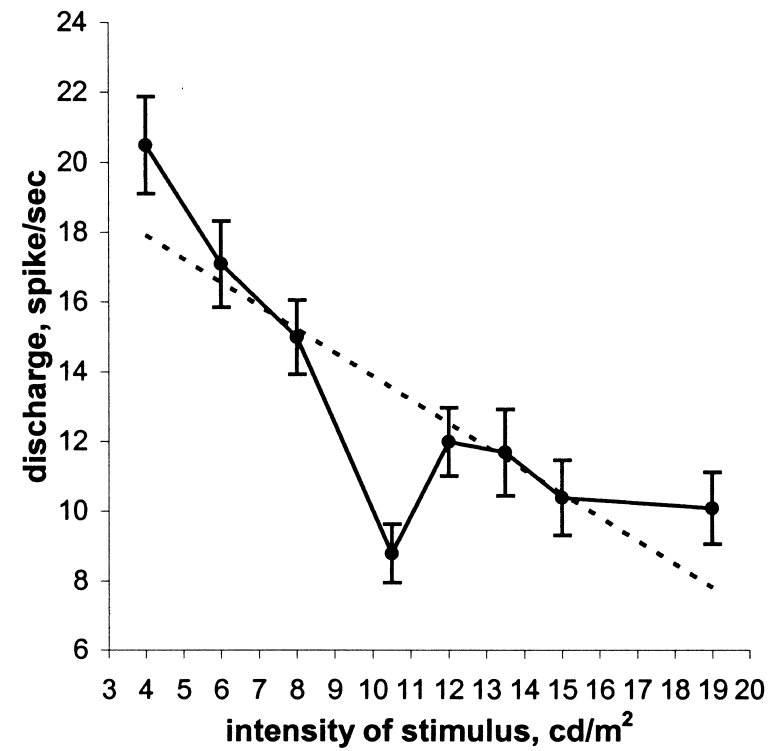

Figure 6. Dependence of neurons' tonic discharge on the increase of black-white intensity of presented stimuli. As a reliability of test, the error in mean was discarded. Abscissa: the intensity of stimuli $\left(\mathrm{Cd} / \mathrm{m}^{2}\right)$. Ordinate: the average frequency of spikes per 1 second of analysis (during identical stimuli changes).

A, B: Reactions of neurons in the lateral geniculate nucleus with increasing and decreasing level of tonic activity.

C, D: The reactions of neurons in superior colliculus with increasing and decreasing level of tonic activity. 
activity. A tonic discharge in a pure form (without the influence on it of a response's phasic components) can be recorded during a change in identical stimuli. We conducted such recordings for all stimuli. It must be noted that approximately half the neurons in all studied sections of the rabbit's visual system were characterized by a fairly stable tonic response, regardless of what the color was or the intensity of the stimuli. The other half of the neurons demonstrated a change in tonic activity depending on the stimuli's characteristics.

Neurons in the lateral geniculate nucleus and superior colliculus proved possible to be divided into two groups: with a monotonically increasing and a monotonically waning frequency of tonic discharge when increasing the brightness of presented stimuli. Such gradual dependences of the neurons' discharge frequency on the intensity of stimuli are
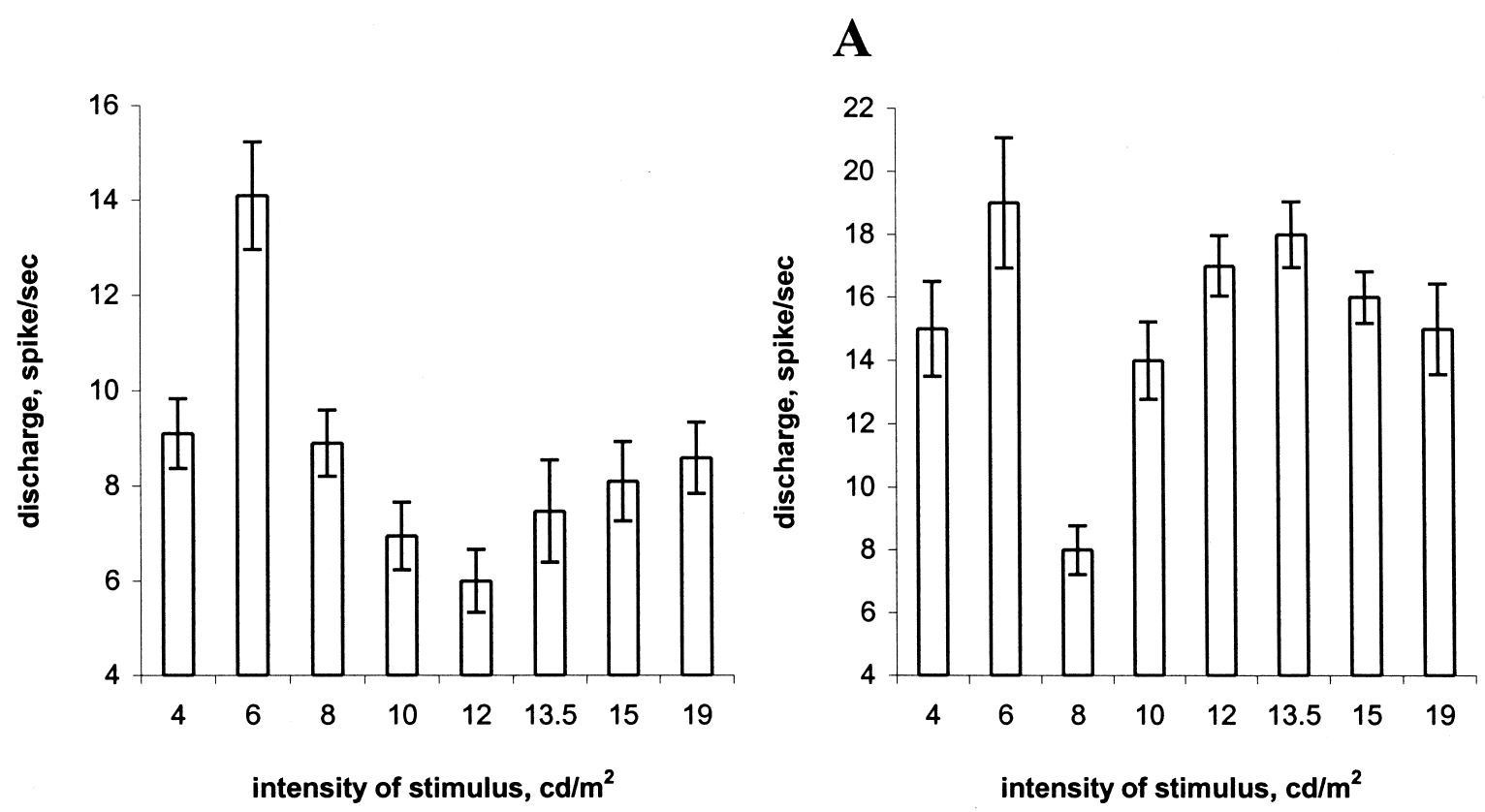

\section{B}
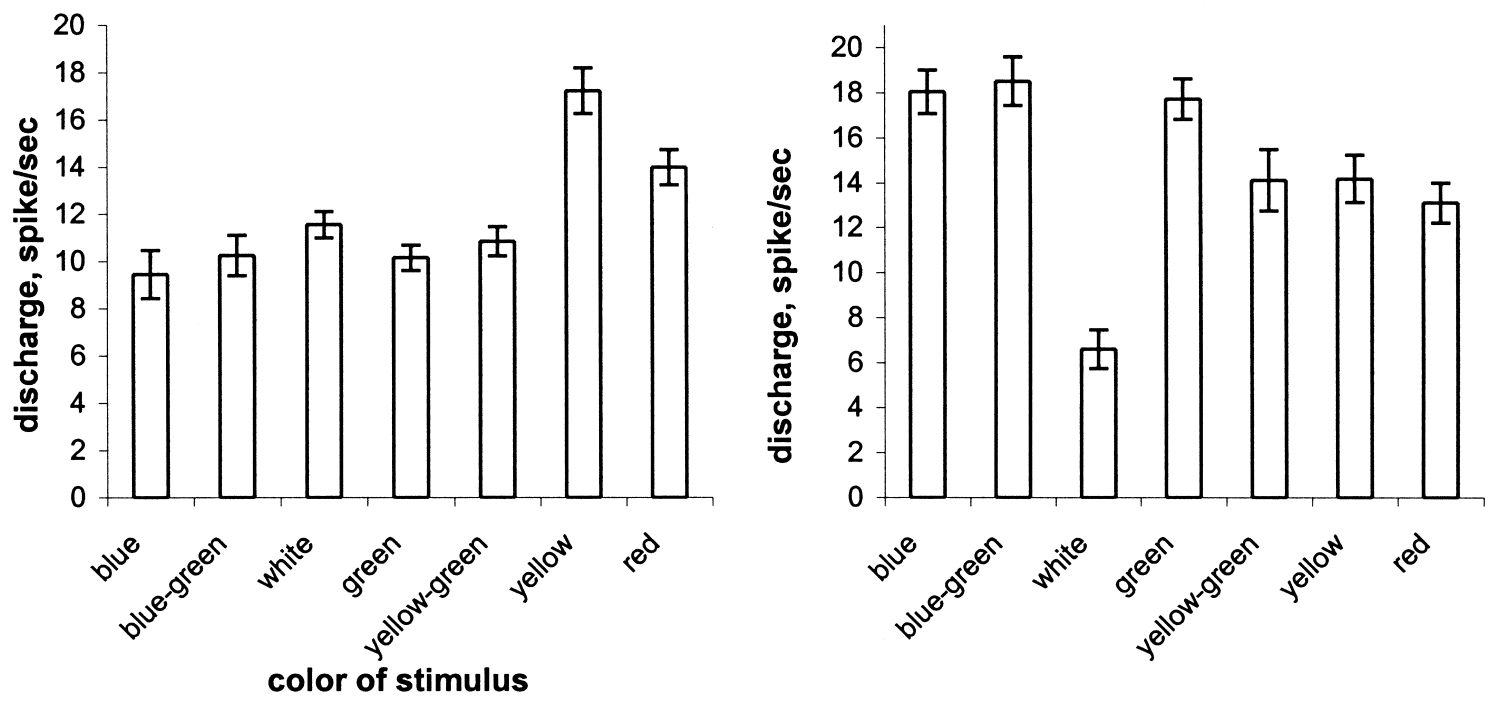

color of stimulus

Figure 7. Examples of tonic activity of individual neurons in the rabbit's visual cortex showing selective properties.

A. Examples of neurons selectively revealing stimuli of a determined intensity by increase or decrease in tonic response.

B. Examples of neurons selectively revealing determined color stimuli by an increase or fall in discharge. The histograms show the error in mean. 
presented in Figure 6. As regards the cortical neurons, a similar gradual dependency of tonic discharge on the change in intensity of stimuli was not discovered. A significant part of the neurons in the cortex did not react to a change in brightness or color in the stimuli. However, among the studied neurons cells were found selectively reacting to this or that stimulus with an increase or reduction in tonic activity. Examples of such reactions are presented in Figure 7. It can be said that such neurons exhibit detector (selective) properties, distinguishing this or that stimulus by a determined frequency of impulsation in the tonic response.

\section{Discussion}

Thus, in experiments to record the neuron activity in response to a change in color stimuli, we discovered neurons reacting with a physical response to stimuli differing, both in color tone and intensity, and also exclusively in intensity. The amount of this phasic response correlates to the interstimulus difference. Compiling matrices from the amount of phasic response under different changes and processing them by factor analysis, it proved possible to reconstruct the sensory space of stimuli for an individual neuron (Figure 2). In the case where stimuli differed only in intensity, the sensory spaces were two-dimensional, but also in the case of a change in variously-bright stimuli, the spaces also had a two-dimensional structure (for the majority of neurons in the lateral geniculate nucleus and a third of neurons in the cortex and colliculus). The axes of such a space (Figures 3, 4) were interpreted by us as the interaction of two mechanisms participating in the processing of intensity information - bright and dark.

In psycho-physical experiments on man (Izmailov et al., 1989) to categorize stimuli, where stimuli were presented on a screen with sufficiently large intervals, a somewhat different structure of achromatic space was revealed: the stimuli were arranged on an arc within one quadrant, where the maximum dark and maximum bright stimuli had the greatest coordinates along different axes. In the case of presenting stimuli of a disk-ring type (for man) or simultaneous presentation of two stimuli to animals when developing differentials, the reconstructed achromatic spaces were a semi-circle. At the basis of the interpretation of such an 'extension' of the achromatic space lies the influence of the simultaneous contrast when delivering the stimuli in pairs or one stimulus on the background of another: thus, the blackness sensation arising (i.e., when the stimulus is darker than the turned-off screen) is only possible where there is a contrasting stimulus (Fomin, Sokolov, \& Vaitkiavichus, 1978; Sokolov \& Izmailov, 1984). In the given case, where there is instantaneous change of stimuli, the effect of sequential contrast is observed, which can be exhibited in a similar way when constructing the sensory space on the basis of a change in the neurons' discharge frequency.
The quantitative analysis showed that in the lateral geniculate nucleus neurons predominate which react exclusively to the brightness properties of stimuli. In the lateral geniculate nucleus, $86 \%$ of those studied were such neurons, at the same time as in the visual cortex it was approximately one third. Sensory spaces revealed on the basis of such neurons' reactions were two-dimensional, both under presentation of brightness, and also of color stimuli (Figures 3.B and 4.B). This can testify to a definite specialisation of neurons in the lateral geniculate nucleus in terms of rapid processing of the most significant information - the difference in brightness of this or that stimulus. Doubtless, such qualitative conclusions require a greater number of studied neurons, however, the available facts may testify to the fact that the convergence of all the information necessary to analyse the color of stimuli occurs in neurons in the visual cortex.

The spaces of variously-bright stimuli reconstructed according to the physical discharges of other neurons had a four-dimensional structure. Each color stimulus in the space presented a combination of stimulations for four neurons: two achromatic (bright and dark) and two chromatic (red-green and blue-yellow with reduced properties). Combinations of stimulations of these neurons form stimulation vectors, equal in length so that the full set of stimuli was presented as points on a spherical surface (hypersphere) in a four-dimensional space (Figure 5). Spaces reconstructed according to the data from neurons of different sections in the rabbit's visual system were isomorphic. This may testify to the fact that the difference discharge which is discovered in neurons' responses, both in sub-cortical and in cortical structures, is already formed at the retina level and transmitted to the geniculate body, colliculus, and visual cortex along separate branches of the visual nerve. Confirmation of this may be the work on studying electroretinograms of frogs in which it was shown that ' $b$ ' and ' $d$ ' waves are determined by the difference in brightness or color of stimuli, forming a two-dimensional or fourdimensional vector space (Zimachev et al., 1991).

Finally, the question should be discussed as to the role of the neuron's tonic response. In the majority of neurons it changes dynamically in association with the increase in intensity (Figure 6). For one group of neurons the frequency of this discharged linearly grows with the increase in brightness difference; for the other group of cells - it linearly falls. Such a principle was typical for neurons in sub-cortical structures, but for cortical neurons such an effect was not discovered. In the visual cortex we observed maximum and minimum tonic discharges to this or that stimulus intensity (Figure 7). Consequently, it may be concluded that in the visual cortex a part of the neurons, at least, have a tonic discharge selectively tuned to some intensity of stimulus or color tone, which characterizes the neurons in the cortex as detectors selectively reacting to different intensities of stimuli or their color. The preponderance of a gradual dependence 
of the tonic-discharge frequency on the intensity of stimuli for neurons in the geniculate nucleus permits the assumption that the said cells are pre-detectors for selective detectorneurons in the visual cortex.

The study of neurons in the superior colliculus presented special interest as this structure is not a relay on the path of visual information from the retina to the cortex and at the same time receives signals both from the retina, and from higher sections of the analyser.

The superior colliculus has a layered structure. Surface layers receive direct inputs from the retina; these layers are projected in the lateral geniculate nucleus and pretectum, affecting, presumably, visual perception. However, the surface, visual layers receive direct input also from the visual cortex. Projections of the upper layers extend also to the deep layers of the colliculus itself, which are multi-modal and premotor by nature. Neurons in the deep layers participate in the organization of the eyes' saccadic movements (May, 2005; Shneider \& Kastner, 2005).

In our experiments the recording of neurons was conducted from surface, visual layers of the rabbit's superior colliculus. A characteristic of the neurons in the superior colliculus was the presence of two clearly expressed phasic discharges - early in the range of 50-90 Ms and later in the range of 120-300 Ms after a change in stimuli (Figure 1). Sensory spaces reconstructed according to the early phasic discharge had a two-dimensional structure and were isomorphic to the spaces of cells in the geniculate nucleus and visual cortex. Such achromatic spaces were reconstructed both under the presentation of stimuli differing in brightness, and in brightness and color (Figures 3.C and 4.C).

Analysis of the later discharge of neurons in the superior colliculus showed that for the overwhelming number of neurons four-dimensional color spaces could be reconstructed on the basis of the secondary discharge, similar to those obtained on the basis of the early discharges of neurons in the superior colliculus and visual cortex (Figure 5). How is such a phenomenon to be explained? According to data from certain authors (Marocco \& Li, 1977; Shneider \& Kastner, 2005) cells in the surface layers of the superior colliculus showed chromatic opposition. Corticotectal neurons in the rabbit's visual cortex have a large influence on the discharge of the colliculus' cells, similar to the ascending influences of cells in the geniculate nucleus on neurons in the rabbit's visual cortex (Bereshpolova, Stoelzel, Gusev, Bezdudnaya, \& Swadlow, 2006). Pertaining to such influences is the information already processed in the visual cortex and transmitted to cells in the colliculus, including also that on color differences (Jassik-Gerschenfeld, 1965; Ottes, Van Gisbergen, \& Eggemont, 1987). Presumably, for the generation of saccades and, especially, rapid ones, the animal needs first and foremost early information on the brightness contrast in different sections of its field of vision. This is obviously expressed in the fact that all the two-dimensional achromatic spaces are discovered when analyzing the average number of spikes in the early discharge. As regards neurons with a four-dimensional space, they, presumably, receive the already processed information on color differences from the visual cortex and exhibited in the later discharge.

Finally, analysis of the tonic discharge of neurons in the colliculus showed that in the given structure there is a set of neurons which exhibit a gradual growth or fall in tonic discharge to the increasing intensity of black-white stimuli (Figures 6.A and B). This circumstance also helps the neurons in the upper layers of the superior colliculus to transmit fairly rapidly the visual information on differences in the intensity of stimuli to neurons in the lower layers to produce and correct saccades.

Thus, in our work in different sections of the rabbit's visual system, two groups of neurons were discovered. One group is only tuned to distinguish the intensity of stimuli. The ratio of these neurons in the structures of the visual system appears thus: lateral geniculate nucleus $-86 \%$, superior colliculus $-30 \%$, and visual cortex $-30 \%$. The other group includes more complicated neurons distinguishing both the intensity of stimuli and the color tone. In this way these neurons analyse immediately the two attributes of the visual stimulus, which is reflected in the more complicated fourdimensional sensory space that can be reconstructed according to their responses. The ratio of such neurons in different parts of the rabbit's visual system is such: lateral geniculate nucleus $-14 \%$, superior colliculus $-19 \%$, and visual cortex $-22 \%$. There are more of them in the primary visual cortex, as is logical inasmuch as the visual cortex performs the more complicated integrative functions. At the present time, more work is appearing noting that already at the early stages of the visual system, including in the primary visual cortex, individual neurons are tuned not to one attribute of a visual stimulus, but to several. Many neurons in the V1 field are selective to a combination of such properties as color, orientation, disparity, and direction of movement (Leventhal, Thompson, Liu, Zhou, \& Ault, 1995). One work should be especially noted (Roelfsema, 2006), where it is discussed that the fundamental task of vision is the grouping of elements in the form of an object and its separation from other objects and the background. Basic grouping is performed by individual neurons tuned to multiple stimulus properties: orientation, color, and others. This grouping occurs rapidly, which allows the animal (and man) top react to changes in the environment and come to a decision with minimal interval. In our work cells were discovered which rapidly (in an interval of 50$90 \mathrm{Ms}$ from the start of the response) react to several attributes of the visual stimulus (color, intensity).

We are continuing research and are now studying the interaction on neurons in the rabbit's visual cortex of such visual-stimulus attributes as orientation and intensity. Preliminary experiments showed that such interaction also exists.

Summing up, it should be said that the sensory spaces of neurons in the superior colliculus revealed on the basis 
of the spikes' frequency in the early and late discharges were isomorphic to the spaces of neurons in other sections of the visual analyser (Polianskii, Evtikhin, \& Sokolov, 2006; Polianskii, Evtikhin, Sokolov, \& Alymkulov, 2007), and also to spaces obtained by other methods: on the basis of an analysis of the amplitudes of component N85 in evoked potentials in the visual cortex (Polianskii et al., 2000), and also on the basis of the probability of reactions under conditioned reflex differentials (Polianskii et al., 1998). This fact may serve as confirmation of Sokolov's hypothesis (Sokolov, 2000) on the vector coding of sensory information in the brain of animals and man.

\section{Conclusions}

The use of the frequency of the spike discharge in neurons' phasic reactions under changes in color stimuli permits the reconstruction of sensory spaces for individual cells in the rabbit's visual system.

In the rabbit's visual cortex, lateral geniculate nucleus, and superior colliculus, two groups of neurons were discovered. One group of cells is tuned exclusively to distinguish the intensities of stimuli, the other - to distinguish both intensities and also the color tone of the stimuli. On the basis of the phasic responses of neurons in the first group a two-dimensional achromatic space was able to be reconstructed, reflecting the interaction of the brightness and darkness mechanisms. The reactions of neurons in the second group revealed a four-dimensional space with two color and two achromatic axes.

Sensory spaces of studied neurons were isomorphic and reflect the transmission of a signal on the brightness and color difference between stimuli, formed, presumably, by retina cells and transmitted along parallel paths to various zones of the visual analyser.

Two-dimensional brightness and four-dimensional color spaces of neurons principally coincided with spaces revealed on the basis of electro-physiological methods (recording of cortical visual evoked potentials), and also on the basis of probability of the animals' responses under conditioned reflex differentials. Such a coincidence speaks for the hypothesis of vector coding of information in the brain's sensory systems.

A phasic discharge of neurons in the visual system appears where there is a brightness or color contrast between presented stimuli. The tonic response of neurons in the visual cortex is characterized by the selectivity of the response to a definite intensity or color and serves to detect the given properties of the presented stimulus. Tonic discharges of neurons in the lateral geniculate nucleus and superior colliculus show gradual changes under an increase in the intensity of stimuli and may reflect the properties of these cells as pre-detectors in relation to selective detectors in the visual cortex.

\section{References}

Bereshpolova, Y., Stoelzel, C.K., Gusev, A.G., Bezdudnaya, T., \& Swadlow, H.A. (2006). The impact of a corticotectal impulse on the awake superior colliculus. Journal of Neuroscience, 26, 2250-2259.

Evtikhin, D.V., Latanov, A.V., \& Sokolov, E.N. (1997). Perceptual brightness space in the carp (Cyprinus carpio L.). Neuroscience and Behavioral Physiology, 27, 17-26.

Evtikhin, D.V., Latanov, A.V., \& Sokolov, E.N. (1998). Brightness perceptive space in monkeys (rhesus macaques). Neuroscience and Behavioral Physiology, 28, 285-293.

Fomin, S.V., Sokolov, E.N., \& Vaitkiavichus, G.G. (1978). Iskusstvennie organi chuvstv. Problemi modelirovaniya sensornih system [The man-made sensor organs. The problems of modeling of sensory systems]. Moscow: Nauka.

Izmailov, Ch.A., Sokolov, E.N., \& Chernorizov, A.M. (1989). Psichofiziologia cvetovogo zreniya [The psychophysiology of color vision]. Moscow: Izdatelstvo MGU.

Izmailov, Ch.A., \& Sokolov, E.N. (1991). Spherical model of color and brightness discrimination. Psychological Science, 2, 249259.

Jacobs, G.H. (1993). The distribution and nature of color vision among the mammals. Biological Reviews of the Cambridge Philosophical Society, 68, 413-471.

Jassik-Gerschenfeld, D. (1965). Somesthetic and visual response of superior colliculus neurons. Nature, 208, 898-900.

Latanov, A.V., Leonova, A.Yu., Evtikhin, D.V., \& Sokolov, E.N. (1997). Comparative neurobiology of color vision in humans and animals. Neuroscience and Behavioral Physiology, 27, 394-404.

Leventhal, A.G., Thompson, K.G., Liu, D., Zhou, J., \& Ault, S.J. (1995). Concomitant sensitivity to orientation, direction and color of cells in layers 2, 3 and 4 of monkey striate cortex. Journal of Neuroscience, 15, 1808-1818.

Marocco, R.T., \& Li, R.H. (1977). Monkey superior colliculus: Properties of single cells and their afferent inputs. Journal of Neurophysiology, 40, 844-860.

May, P.J. (2005). The mammalian superior colliculus: Laminar structure and connection. Progress in Brain Research, 151, 321-378.

Nuboer, J.F.W., \& Moed, P.J. (1983). Increment-threshold spectral sensitivity in the rabbit. Journal of Comparative Physiology, 151, 353-358.

Nuboer, J.F.W., Van Nuys, W.M., \& Wortel, J.F. (1983). Cone systems in the rabbit retina revealed by ERG-null detection. Journal of Comparative Physiology, 151, 347-352.

Ottes, E.P., Van Gisbergen, J.A., \& Eggemont, J.J. (1987). Collicular involvement in a saccadic color discrimination task. Experimental Brain Research, 66, 465-478.

Polianskii, V.B., Sokolov, E.N., Marchenko, T.Iu., Evtikhin, D.V., \& Ruderman, G.L. (1998). Perceprivnoe cvetovoe prostranstvo krolika [The perceptive color space of the rabbit]. Zhurnal Vysshei Nervnoi Deiatelnosti Im I.P.Pavlova, 48, 496-504.

Polianskii, V.B., Evtikhin, D.V., \& Sokolov, E.N. (1999). Yarkostnie componenti zritelnogo vizvannogo potenciala na cvetovie 
stimuli u krolika [The brightness components of the visual evoked potential to color stimuli in the rabbit]. Zhurnal Vysshei Nervnoi Deiatelnosti Im I.P.Pavlova, 49, 1046-1051.

Polianskii, V.B., Evtikhin, D.V., \& Sokolov, E.N. (2000). Reconstrukciya perceptivnogo prostranstva yarkosti I cveta krolika na osnove zritelnih potencialov i ih sravnenie s dannimi povedencheskih opitov [The reconstruction of the perceptual spaces of brightness and color on the basis of visual evoked potentials and their comparison with the data from behavioral trials]. Zhurnal Vysshei Nervnoi Deiatelnosti Im I.P.Pavlova, 50, 843-854.

Polianskii, V.B., Evtikhin, D.V., \& Sokolov, E.N. (2006). Computation of color and brightness differences by rabbit visual cortex neurons. Neuroscience and Behavioral Physiology, 36, 235-245.

Polianskii, V.B., Evtikhin, D.V., Sokolov, E.N., \& Alymkulov, D.E. (2007). Computation of color and brightness differences by neurons in the lateral geniculate nucleus of the rabbit. Neuroscience and Behavioral Physiology, 37, 237-247.

Roelfsema, P.R. (2006). Cortical algorithms for perceptual grouping. Annual Review of Neuroscience, 29, 203-227.

Schneider, K.A., \& Kastner, S. (2005). Visual responses of the human superior colliculus: A high-resolution functional magnetic resonance imaging study. Journal of Neurophysiology, 94, 2491-2503.
Sokolov, E.N., \& Izmailov, Ch.A. (1984). Cvetovoe zrenie [Color vision]. Moscow: Izdatelstvo MGU.

Sokolov, E.N. (2000). Perception and the conditioning reflex: Vector encoding. Inernational Journal of Psychophysiology, 35, $197-$ 217.

Sokolov, E.N. (2003). Vospriyatie i uslovnii reflex: novii vzglyad. [Perception and condition reflex: new point of view] Moscow: Izdatelstvo UMK Psihologia.

Vartanov, A.V., Polianskii, V.B., Sokolov, E.N., \& Evtikhin, D.V. (1998). Osobennosti cvetovogo perceptivnogo prostranstva protanomalov. [The characteristics of the color perceptive space in protanomals]. Zhurnal Vysshei Nervnoi Deiatelnosti Im I.P.Pavlova, 48, 788-796.

Wyrwicz A.M., Chen N., Li L., Weiss C., \& Disterhoft J.F. (2000). fMRI of visual system activation in the conscious rabbit. Magnetic Resonance in Medicine, 44, 474-478.

Zimachev, M.M., Shekhter, E.D., Sokolov, E.N., Naatanen, R., Nyman, G., \& Izmailov, Ch.A. (1991). Differencirovka cvetovih signalov setchatkoi lyagushki [The differentiation of color signals by the frog retina]. Zhurnal Vysshei Nervnoi Deiatelnosti Im I.P.Pavlova, 41, 518-527.

Received May 11, 2007 Revision received June 13, 2008 Accepted July 07, 2008 